\title{
TINGKAT KEPUASAN LAYANAN CUSTUMER SERVICE BERDASARKAN METODE WEBQUAL 4.0 PADA PT TRITANA DENGAN PLS-SEM
}

\author{
Andi Arfian $^{1}$, Dede Mustomi ${ }^{2}$,Juarni Siregar ${ }^{3}$, Adelia Alvi Yana $^{4}$ \\ Program Studi Sistem Informasi ${ }^{134}$, Program Studi Administrasi Bisnis ${ }^{2}$ \\ Fakultas Teknologi Informasi ${ }^{1,4}$, Fakultas Teknik dan Informatika ${ }^{3}$ \\ Fakultas Ekonomi dan Bisnis ${ }^{2}$ \\ Universitas Nusa Mandiri ${ }^{1,4}$, Universitas Bina Sarana Informatika ${ }^{2,3}$, \\ andi.afn@nusamandiri.ac.id ${ }^{1}, \underline{\text { dede.ddo@bsi.ac.id }}{ }^{2}$, juarni.jsr@bsi.ac.id ${ }^{3}$ \\ , adelia.aav@nusamandiri.ac.id ${ }^{4}$
}

Received: April 26, 2021. Revised: May 05, 2021. Accepted: May 22, 2021. Published: June 20, 2021. Issue Period: Vol.5 No.1 (2021), Pp.89-93

\begin{abstract}
Abstrak: Dalam kancah dunia bisnis, terutama untuk bisnis jasa, terdapat banyak strategi untuk membuat sebuah bisnis sukses. Selain strategi pemasaran yang handal, sebuah bisnis juga membutuhkan pelayanan prima sehingga dapat membuat konsumen nyaman dan senang. Setiap perusahaan akan berlomba lomba untuk memberi layanan yang terbaik bagi konsumennya yang membuat pelanggan menjadi puas sehingga dapat meningkatkan aspek lainnya seperti penjualan, profit Pada penelitian ini penulis menganalisa aspek dari web layanan Customer Service yang ada pada PT Tratana yaitu dengan menganalisa sistem layanan prima kepada konsumen dengan mengunakan model Webqual4 dan Pengolahan datanya dengan Metode PLS-SEM dan dari hasil penelitian ini diharapkan bisa mengetahui sejauh mana efektifitas dan kepuasan konsumen setelah membeli produk yang mereka beli dan hasil analisa didapat banyak variable yang tidak signifikan terhadap kepuasan konsumen,
\end{abstract}

Kata kunci: SEM-PLS, Webqual4, Web Layanan Service

\begin{abstract}
In the world of business, especially for service businesses, there are many strategies to make a business successful. In addition to a reliable marketing strategy, a business also needs excellent service so that it can make consumers comfortable and happy. Each company will compete to provide the best service for its customers which makes customers satisfied so that it can improve other aspects such as sales, profit. In this study the authors analyzed aspects of the web service service available at PT Tratana, namely by analyzing the excellent service system to consumers with Using the Webqual4 model and data processing with the Pls-Sem method from the results of this study it is expected to know the extent to which the effectiveness and satisfaction of consumers after buying the products they buy from the analysis results obtained by many variables that are not significant to customer satisfaction.
\end{abstract}

Keywords: SEM-PLS, Webqual4, Consumer Service Web

DOI: 10.52362/jisicom.v5i1.453

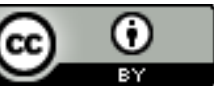

Ciptaan disebarluaskan di bawah Lisensi Creative Commons Atribusi 4.0 Internasional. 


\section{PENDAHULUAN}

Pelayanan prima merupakan salah satu kunci penting dalam menjalankan sebuah bisnis, terutama untuk bisnis jasa. Saat ini banyak perusahaan yang menjual produk atau jasa yang serupa, namun pelayanan yang diberikan berbeda. Dan hal inilah yang dapat membedakan satu perusahaan dengan perusahaan yang lain. Salah satu tujuan dari memberikan pelayanan yang prima adalah memberikan kepuasan terhadap pelanggan yang membeli [1]yang memanfaatkan internet sebagai media dalam mengembangkan proses bisnisnya, melalui website tersebut transaksi layanan service dapat dilakukan secara online. Banyak hal menguntungkan yang didapat dari transaksi online baik dari pihak penjual ataupun pembeli, bertahan dan terus berkembang di era persaingan situs ecommerce saat ini dan dimasa yang akan datang maka perlu dilakukan penelitian. Analisa penelitian ini bertujuan untuk mengetahui penilaian konsumen terhadap kualitas website layanan Konsumen, Mengetahui signifikansi tingkat kepuasaan pengguna website Layanan Service Konsumen terhadap usability (kemudahan), information quality (kualitas informasi), interaction quality (kualitas informasi), sehingga hasil dari penelitian dapat menjadi masukan bagi PT Tratana guna melakukan peningkatan dalam kualitas website untuk meningkatkan kepuasaan pengguna terhadap website ini. Penelitian ini memiliki rumusan hipotesis, yaitu: H0 : Tidak adanya penilaian positif kepuasan pengguna terhadap Kegunaan (Usability). H1 : Adanya penilaian positif kepuasan pengguna terhadap Kegunaan (Usability). H2 : Tidak Adanya penilaian positif kepuasan pengguna terhadap kualitas informasi (information quality). H3 : Adanya penilaian positif kepuasan pengguna terhadap kualitas informasi (information quality). H4 : Tidak Adanya penilaian positif kepuasan pengguna terhadap kualitas Interaksi (interaction quality). H5 : Adanya penilaian positif kepuasan pengguna terhadap kualitas Interaksi (interaction quality). [2].

\section{METODE DAN MATERI}

[1]. Bagian ini memberikan pedoman bagi penulis tentang elemen-elemen penulisan dan ilustrasi saat menyiapkan naskah. Penelitian ini dilakukan penulis dengan tahapan-tahapan tahapan yang dimulai dari menentukan rumusan masalah kepuasaan pengguna terhadap website Layanan Konsumen. Setelah itu penulis mempelajari berbagai penelitian sebelumnya sebagai tolak ukur atau acuan untuk menyelesaikannya, selanjutnya penulis membuat sebuah kuesioner dengan mengikuti dimensi webqual 4.0 dan menyebarkan kuesioner untuk mendapatkan data primer. Data hasil kuesioner di uji validitas, uji reliabilitasnya, Setelah uji validitas dan reliabilitas maka dapat diuji dengan regresi linier berganda. Setelah mendapatkan hasil pembahasan baru dapat diambil kesimpulan dan saran berdasarkan keseluruhan hasil dari penelitian. Dalam penelitian website layanan service mengunakan metode Suatu pengukuran untuk mengukur sebuah kualitas . Evaluasi model pengukuran untuk responden Konsumen di PT Tritana, [2], Metode Webqual Suatu pengukuran untuk mengukur sebuah kualitas dari sebuah website berdasarkan instrument penelitian yang dikategorikan dalam empat variabel yaitu : Usability, Information Quality, Interaction Quality, dan Overall Impression disebut dengan WebQual [3], SEM dengan PLS merupakan suatu teknik alternatif pada analisis SEM dimana data yang dipergunakan tidak harus berdistribusi normal multivariat. Pada SEM dengan PLS nilai variabel laten dapat diestimasi sesuai dengan kombinasi linear dari variabel-variabel manifest yang terkait dengan suatu variabel laten serta diperlakukan untuk menggantikan variabel manifest [4].

[3] Pengujian hipotesis dalam penelitian ini menggunakan metode Partial Least Square (PLS). PLS merupakan metode alternatif analisis dengan Structural Equation Modelling (SEM) yang berbasis variance. Keunggulan metode ini adalah tidak memerlukan asumsi dan dapat diestimasi dengan jumlah sampel yang relatif kecil[4]

\section{PEMBAHASAN DAN HASIL}

[4]. Bagian ini memberikan pedoman bagi penulis tentang elemen-elemen penulisan dan ilustrasi saat menyiapkan naskah. Penelitian ini dilakukan penulis dengan tahapan-tahapan tahapan yang dimulai dari menentukan rumusan masalah kepuasaan pengguna terhadap website Layanan Konsumen. Setelah itu penulis mempelajari berbagai penelitian sebelumnya sebagai tolak ukur atau acuan untuk menyelesaikannya, selanjutnya penulis membuat sebuah kuesioner dengan mengikuti dimensi webqual 4.0 dan menyebarkan

DOI: $10.52362 /$ jisicom.v5i1.453

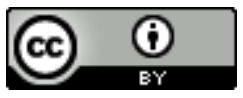

Ciptaan disebarluaskan di bawah Lisensi Creative Commons Atribusi 4.0 Internasional. 
Journal of Information System, Informatics and Computing

Website/URL: http://journal.stmikjayakarta.ac.id/index.php/jisicom

Email: jisicom@stmikjayakarta.ac.id , jisicom2017@gmail.com

kuesioner untuk mendapatkan data primer. Data hasil kuesioner di uji validitas, uji reliabilitasnya, Setelah uji validitas dan reliabilitas maka dapat diuji dengan regresi linier berganda. Setelah mendapatkan hasil pembahasan baru dapat diambil kesimpulan dan saran berdasarkan keseluruhan hasil dari penelitian. Dalam penelitian website layanan service mengunakan metode Suatu pengukuran untuk mengukur sebuah kualitas . Evaluasi model pengukuran untuk responden Konsumen di PT Tritana, [4]

[3]merupakan nilai koefisen jalur atau besarnya hubungan atau pengaruh konstruk laten yang dilakukan dengan prosedur Bootstrapping. Pengujian hipotesis dalam penelitian ini menggunakan metode Partial Least Square (PLS). PLS merupakan metode alternatif analisis dengan Structural Equation Modelling (SEM) yang berbasis variance. Keunggulan metode ini adalah tidak memerlukan asumsi dan dapat diestimasi dengan jumlah sampel yang relatif kecil [5]. Dalam Penelitian ini mengunakan Prosedur Analisis Adapun langkah-langkah analisis dalam penelitian ini adalah sebagai berikut: Merancang model struktural (inner model), Merancang model pengukuran (outer model), Mengkonstruksi diagram jalur berdasarkan model, Mengkonversi diagram jalur ke sistem persamaan, Melakukan estimasi parameter, Mengukur kebaikan model, Melakukan pengujian hipotesis, Interpretasi hasil analisis

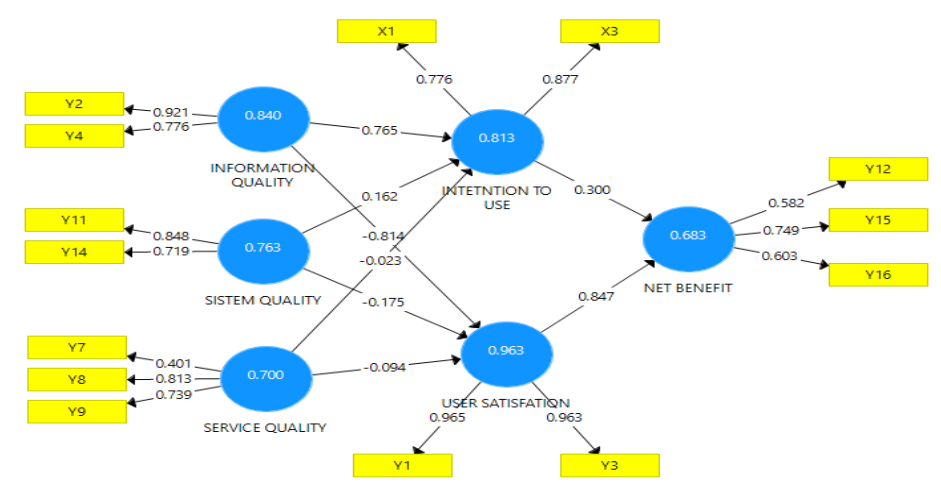

Gambar 1. Parameter Model

Penaksiran atau estimasi parameter model pada Gambar 1 dilakukan dengan menggunakan algoritma PLSSEM yang didasarkan pada metode Ordinary Least. Square (OLS) . Algoritma PLS-SEM dikerjakan menggunakan model regresi parsial yang dilakukan secara iterasi dalam dua tahap. Tahap pertama adalah penaksiran skor konstruk. Tahap kedua adalah penaksiran nilai outer loadings, path coefficients dan nilai R2 dari variabel laten endogen. Nilai outer loadings, di estimasi melalui regresi sederhana pada setiap indikator terhadap masing-masing konstruksnya. Sedangkan path coefficients dan nilai R2 diestimasi melalui analisis regresi antar variabel endogen. Algoritma PLS-SEM dihentikan ketika konvergensi sudah tercapai atau nilai maksimal angka iterasi tercapai. Data pada penelitian ini merupakan data primer yang dikumpulkan melalui penyebaran kuesioner terhadap 78 Costumers pengguna Digital Copier Pada PT Tratana selama masa pademi Covid19 2020-2021. Evaluasi Model Pengukuran Reflective model pengukuran dilakukan dengan memeriksa (a) internal consistency reliability menggunakan statistic composite reliability, (b) indikator reliability menggunakan the indikator's outer loadings, (c) Convergent validity menggunakan statistic AVE dan (d) discriminant validity menggunakan Cross loadings.

Tabel 2. Construct Reliability and Validity

\begin{tabular}{lcccc}
\hline & $\begin{array}{c}\text { Cronbach's } \\
\text { Alpha }\end{array}$ & rho_A & $\begin{array}{c}\text { Composite } \\
\text { Reliability }\end{array}$ & $\begin{array}{c}\text { Average Variance } \\
\text { Extracted }(A V E)\end{array}$ \\
\hline Qualitas Informasi & 0.924 & 0.986 & 0.963 & 0.928
\end{tabular}

DOI: $10.52362 /$ jisicom.v5i1.453

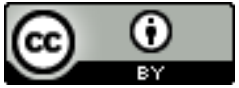

Ciptaan disebarluaskan di bawah Lisensi Creative Commons Atribusi 4.0 Internasional. 
Journal of Information System, Informatics and Computing

Website/URL: http://journal.stmikjayakarta.ac.id/index.php/jisicom

Email: jisicom@stmikjayakarta.ac.id, jisicom2017@gmail.com

Qualitas Interaksi layanan

Qualitas Interface Penguna

Tingkat Kepuasan

Usability

0.639
0.688
1.000
0.593

0.639

1.000

0.593

1.169
0.626
1.000
0.593

1.169

0.593
0.818
0.731
1.000
0.675

0.698

0.594

1.000

0.525

Nilai composite reliability (Tabel 2) untuk semua konstruk lebih besar dari 0,798 sehingga dapat dikatakan bahwa konstruk memiliki konsistensi internal yang cukup tinggi.dikatakan bahwa konstruk memiliki konsistensi internal yang cukup tinggi. Sebelum dilakukan pengujian signifikansi model struktural, terlebih dahulu dilakukan pengujian kolinieritas antara variabel kualitas antar muka, kualitas informasi, kualitas interaksi layanan dan usability terhadap tingkat kepuasan melalui statistik VIF. Semua nilai VIF lebih besar dari 0,2 dan lebih kecil dari 5 (Tabel 3).

Tabel 3. Perbandingan nilai Composite Reliability

\begin{tabular}{lccc}
\hline & Std & T Static & P Values \\
& Deviasi & & \\
\hline Qualitas Informasi-> Tingkat Kepuasan & 0.924 & 0.986 & 0.963 \\
Qualitas Interaksi layanan-> Tingkat Kepuasan & 0.639 & 1.169 & 0.818 \\
Qualitas Interface Penguna-> Tingkat Kepuasan & 0.388 & 0.626 & 0.731 \\
Usability->Tingkat Kepuasan & 1.000 & 1.000 & 1.000 \\
\hline
\end{tabular}

Tabel 4. Uji Hipotesis

\begin{tabular}{lll}
\hline & UJI Hipotesis & Keterangan \\
\hline H1 & Qualitas Interface Penguna Berpengaruh Signifikan Terhadap Tingkat Kepuasan & DiTerima \\
H2 & Qualiats Interaksi layanan Berpengaruh terhadap tingkat kepuasan & DiTerima \\
H3 & Qualitas Informasi Berpengaruh terhadap Tingkat kepuasan & D Terima \\
H4 & Usability Berpengaruh dengan tingkat Kepuasan & Di terima \\
\hline
\end{tabular}

Berdasarkan tabel 3 hasil dari Hipotesis pertama dapat disimpulkan bahwa

a. Hipotesi ke 1,H1: Qualitas Interface Penguna akan berpengaruh Signifikan terhadap kepuasan Layanan Service, menghasilkan nilai P-value 0.963Tidak signifikan dengan demikian Ho diterima artinya Tidak ada pengaruh antara Qualitas Interface penguna yang disajikan di Service layanan terhadap kepuasan Constumer . hal ini disebabkan content dari layanan service kurang Lengkap dalam penyajiaan informasi dan kurang memeunhi kebutuhan Contumer,

b. Hipotesis ke 2, H2:Kualitas Interaksi Layanan ( Format) akan berpengaruh signifikan terhadap Kepuasan Contumer,Berdasarkan hasil P-Value didapat nilai 0.818 Tidak signifikan dengan demikian Ho diterima artinya tidak ada pengaruh signifikan terhadap tingakt kepuasan .

c. Hipotesis ke 3, H3: Kualitas Informasi akan berpengaruh signifikan terhadap tingkat kepuasan menghasilkan nilai 0.731 artinydengan mempunyai arti tidak signifikan dengan demikian $\mathrm{H} 0$ diterima dengan arti tidak ada pengaruh signifikan terhadap tinhkat kepuasan disebabkan kurangnya informasi service yang diharapkan ,atau kurangnya layanan cepat kepada contumer.

d. Hipotesi ke 4,H4: Usability Berpengaruh dengan tingkat Kepuasan akan berpengaruh signifikan dengan tingkat kepuasan, nilai yang didapat dari P-Value 1.00 artinya menghasilkan tidak signifikan dengan tingkat kepuasan, Ho diterima tidak ada pengaruh ketepatan waktu terhadap kepuasan contumer disebabkan timeline yang kurang atau ketepatan waktu layanan kurang cepat .

DOI: $10.52362 /$ jisicom.v5i1.453

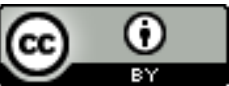

Ciptaan disebarluaskan di bawah Lisensi Creative Commons Atribusi 4.0 Internasional. 


\section{KESIMPULAN}

Dari hasil penelitian untuk menvalidasi kesuksesan system layanan service berdasarkan kepuasan Konsumen dengan model webQual4, Berdasarkan metode Model yang diusulkan kemudahan sistem merupakan pengukuran yang tepat untuk mengukur kualitas system Layanan Konsumen pada PT Tratana, berdasarkan analisa maka diperlukan adanya perbaikan atau peningkatan kualitas informasi, Serta akurasi informasi serta Pelayanan yang cepat terhadap informasi dari Konsumen. Temuan yang jelas adalah bagaimana Konsumen bisa memanfaat system layanan service lebih maksimal, dan juga perlu adanya sosialisasi terhadap pemanfaatan layanan service tersebut terhadap Konsumen. Dan perlunya juga adanya kecepatan Pelayanan service yang cepat dan terpercaya dan handal agar para Konsumen mendapatkan layanan yang terbaik serta tidak kecewa dan beralih ke produk yang lain.

\section{REFERENASI}

[1] A. Ann, G. Alfa, D. Rachmatin, and A. Fitriani, “ANALISIS PENGARUH FAKTOR KEPUTUSAN KONSUMEN DENGAN STRUCTURAL EQUATION MODELING PARTIAL LEAST SQUARE.”

[2] P. Pusfitaningrum and Y. Malau, “Analisis Kualitas Website Jd . Id Terhadap Kepuasan Pengguna Menggunakan,” vol. 02, pp. 109-116, 2018.

[3] A. Arfian, “Analisa Efektifitas Dan Kepuasan Penguna Website Kecamatan Jonggol,” J. Inkofar, vol. 1, no. 2, pp. 13-24, 2018.

[4] A. Arfian, “Analisa Penerimaan Siswa Terhadap G-Class Room Pada Masa Psbb Covid-19 Mengunakan Pendekatan Pls-Sem,” JUSIM (Jurnal Sist. Inf. Musirawas), vol. 5, no. 02, pp. 96-102, 2020.

[5] arfian, “ANALISIS MANFAAT E- AGRICULTURAL MENGUNAKAN METODE SEMPLS (STUDY KASUS LIMAKILO.ID),” 2020.

[6] P. Metode, W. Terhadap, A. Manik, I. Salamah, and E. Susanti, "Pengguna Website Politeknik Negeri Sriwijaya the Impact of Webqual 4 . 0 Method Towards User," J. Elektro dan Telekomun. Terap., pp. 477-484, 2017.

[7] S. Surya, N. Gusriani, and I. Irianingsih, “Analisis Faktor-Faktor yang Memengaruhi Brand Loyalty Gojek Indonesia dengan Efek Mediator Menggunakan Partial Least Square Structural Equation Modeling (PLSSEM)," J. Mat. Integr., vol. 16, no. 2, p. 127, 2020.

[8] E. U. Nikmatus Sholiha and M. Salamah, "Structural Equation Modeling-Partial Least Square untuk Pemodelan Derajat Kesehatan Kabupaten/Kota di Jawa Timur (Studi Kasus Data Indeks Pembangunan Kesehatan Masyarakat Jawa Timur 2013),” J. Sains Dan Seni ITS, vol. 4, no. 2, pp. 169-174, 2015.

[9] W. Panca, "Pengaruh Kualitas Pelayanan Terhadap Loyalitas Wisatawan dan Citra Hotel Melati di Kelurahan Seminyak Kabupaten Badung Bali,” J. Kepariwisataan dan Hosp., vol. 1, no. 1, pp. 65-72, 2017.

[10] D. Radityo and Zulaikha, "Pengujian Model DeLone and McLean Dalam Pengembangan Sistem Informasi Manajemen ( Kajian Sebuah Kasus )," Simp. Nas. Akunt. X, pp. 1-25, 2007.

DOI: $10.52362 /$ jisicom.v5i1.453

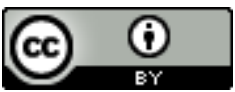

Ciptaan disebarluaskan di bawah Lisensi Creative Commons Atribusi 4.0 Internasional. 